\title{
Significance of Oral Administration of Sodium Perchlorate in Planning Liver-Directed Radioembolization
}

\author{
Amir Sabet ${ }^{* 1}$, Hojjat Ahmadzadehfar ${ }^{* 1}$, Marianne Muckle $^{1}$, Torjan Haslerud ${ }^{1}$, Kai Wilhelm² Hans-Jürgen Biersack $^{1}$, \\ and Samer Ezziddin ${ }^{1}$ \\ ${ }^{1}$ Department of Nuclear Medicine, University Hospital Bonn, Bonn, Germany; and ${ }^{2}$ Department of Radiology, University Hospital \\ Bonn, Bonn, Germany
}

\begin{abstract}
99mTc-macroaggregated albumin (99mTc-MAA) scanning precedes radioembolization of the liver to detect extrahepatic shunting to the lung or gastrointestinal tract. Despite strict preventive measures in the production of $99 \mathrm{mTC}-\mathrm{MAA}$ and in scanning protocols, the images frequently show a gastric concentration of free ${ }^{99 m T c-p e r t e c h n e t a t e, ~}$ hindering accurate evaluation of the gastroduodenal region. Our aim was to evaluate whether oral administration of sodium perchlorate $\left(\mathrm{NaClO}_{4}\right)$ before ${ }^{99 m T c-M A A ~ s c a n n i n g ~ w i l l ~ i m p r o v e ~ i t s ~ a c c u r a c y ~ b y ~}$ blocking free ${ }^{99 m}$ Tc-pertechnetate gastric uptake. Methods: In 144 patients, 171 diagnostic hepatic angiograms combined with a 99mTc-MAA scan were performed; 86 angiograms were performed after oral administration of $\mathrm{NaClO}_{4}$, and 85 were performed without this premedication. Clinical follow-up, esophagogastroduodenoscopy, and angiography served as reference standards. Results: 99mTc-MAA studies showed tracer uptake in the gastric region of 25 patients who did not receive $\mathrm{NaClO}_{4}$. The uptake was interpreted as a free ${ }^{99 m T c}$-pertechnetate concentration in 21 studies and as a 99mTc-MAA accumulation in 4 studies. In 5 patients with a free 99mTc-pertechnetate concentration, aberrant vessels were detected in angiographic reexamination, and 3 patients developed gastrointestinal ulcer. In 7 studies, gastric findings viewed pretherapeutically as free ${ }^{99 m} \mathrm{Tc}$-pertechnetate were retrospectively classified as equivocal. Of the patients receiving $\mathrm{NaClO}_{4}, 2$ showed gastric accumulation of ${ }^{99 m T c-M A A}$ but no equivocal or free ${ }^{99 m T c-p e r t e c h n e t a t e . ~}$ Oral administration of $\mathrm{NaClO}_{4}$ increased the negative predictive value and accuracy of the test concerning the detection of gastric perfusion from $68 \%$ and $69 \%$, respectively, to $93 \%$ and $94 \%$, respectively. Conclusion: Oral administration of $\mathrm{NaClO}_{4}$ before the test angiogram with ${ }^{99 m} \mathrm{Tc}-\mathrm{MAA}$ resulted in effective avoidance of free $99 \mathrm{mTc}$-pertechnetate concentration and, consequently, of equivocal findings in the gastroduodenal region. This technique increased test accuracy and reporter confidence, saved time in reviewing the angiograms, and can improve treatment planning and reduce therapeutic side effects.
\end{abstract}

Key Words: hepatology oncology; SPECT; sodium perchlorate; radioembolization

J Nucl Med 2011; 52:1063-1067

DOI: $10.2967 /$ jnumed.110.083626

\footnotetext{
Received Sep. 27, 2010; revision accepted Apr. 13, 2011

For correspondence or reprints contact: Amir Sabet, Department of Nuclear Medicine, University Hospital Bonn, Sigmund-Freud-Strasse 25, 53127 Bonn, Germany.

E-mail: amir.sabet@ukb.uni-bonn.de

${ }^{*}$ Contributed equally to this work.

COPYRIGHT @ 2011 by the Society of Nuclear Medicine, Inc.
}

O canning with ${ }^{99 m}$ Tc-macroaggregated albumin $\left({ }^{99 m} \mathrm{Tc}-\right.$ MAA) generally precedes radioembolization of the liver to detect extrahepatic shunting to the lung or gastrointestinal tract (1). To avoid dissociated ${ }^{99 \mathrm{~m}} \mathrm{Tc}$-pertechnetate, ${ }^{99 \mathrm{~m}} \mathrm{Tc}-$ MAA should be prepared under strict quality control assessments (2-4) and scintigraphy should be performed within $1 \mathrm{~h}$ of the radiopharmaceutical injection. Despite the preventive measures, a gastric concentration of free ${ }^{99 \mathrm{~m}} \mathrm{Tc}$-pertechnetate is frequently seen in ${ }^{99 \mathrm{~m}} \mathrm{Tc}-\mathrm{MAA}$ images and can hinder the accurate evaluation of the gastroduodenal region. Sodium perchlorate $\left(\mathrm{NaClO}_{4}\right)$ has a great affinity for the sodium-iodine symporter and is safely used for prophylaxis of iodine-induced hyperthyroidism due to iodinated contrast agents (5-7). Our aim was to evaluate whether oral administration of $\mathrm{NaClO}_{4}$ before ${ }^{99 m}$ Tc-MAA scanning will improve its accuracy and diagnostic confidence by facilitating the detection of gastric shunting.

\section{MATERIALS AND METHODS}

\section{Patients}

In 144 patients with primary and secondary hepatic malignancies, 171 diagnostic hepatic angiograms with ${ }^{99 m}$ Tc-MAA were performed. The mean and median ages of the patients were $63 \mathrm{y}$ and $65 \mathrm{y}$, respectively (range, 34-86 y; 50 women [34.7\%] and 94 men [65.3\%]). The patients were categorized into 2 subgroups. The first subgroup consisted of the chronologic first 72 patients, who did not receive $\mathrm{NaClO}_{4}$ before ${ }^{99 \mathrm{~m}} \mathrm{Tc}-\mathrm{MAA}$ assessment, undergoing a total of 85 diagnostic hepatic angiograms combined with administration of ${ }^{99 m}$ Tc-MAA (test angiogram). The second subgroup consisted of the next 72 patients (86 angiograms), who did receive $\mathrm{NaClO}_{4}$ before the test angiogram. Written informed consent was given by each participant before ${ }^{99 \mathrm{~m}} \mathrm{Tc}-\mathrm{MAA}$ assessment.

\section{Procedures}

A preparation kit (GE Healthcare Buchler) was used for the labeling of ${ }^{99 \mathrm{~m}} \mathrm{Tc}$-pertechnetate with macroaggregated human albumin. Quality control was performed according to the instructions of the manufacturer to assess particle size $(10-100 \mu \mathrm{m})$, radiochemical purity $(>95 \%)$, and aggregate stability $(\leq 5 \mathrm{~h})$. To avoid a gastric concentration of free ${ }^{99 \mathrm{~m}} \mathrm{Tc}$-pertechnetate, the test angiograms of subgroup 2 were performed after oral administration of $600 \mathrm{mg}$ of $\mathrm{NaClO}_{4}$. Prophylactic embolization of all visible extrahepatic arteries, including the gastroduodenal and right gastric arteries, was performed as close as possible to the 
intended time of radioembolization to avoid the revascularization of these vessels (maximum interval, $10 \mathrm{~d}$ ). During the angiograms, under blood flow control and depending on the anatomy of the liver, about $185 \mathrm{MBq}(5 \mathrm{mCi})$ of ${ }^{99 \mathrm{~m}} \mathrm{Tc}-\mathrm{MAA}$ were administered intraarterially into the common hepatic artery in 3 tests $(1.8 \%)$, into the proper hepatic artery in 70 tests $(41 \%)$, into the right and left hepatic arteries separately in a single session in 57 tests $(33 \%)$, only into the right hepatic artery in 24 tests (14\%), only into the left hepatic artery in 15 tests (9\%), and superselectively into segmental arteries in 2 tests $(1.2 \%)$. Whole-body anterior and posterior scanning were performed within $1 \mathrm{~h}$ of ${ }^{99 \mathrm{~m} T c-M A A}$ injection with a dual-head $\gamma$-camera (E.Cam; Siemens) to calculate the percentage of liver-to-lung shunting and was followed by planar scintigraphy and SPECT of the upper abdomen to rule out extrahepatic gastrointestinal shunting. Additionally, SPECT/CT using a dual-detector $\gamma$-camera with a mounted 2-row CT scanner (Symbia T2; Siemens) was performed in the last 90 studies to allow better evaluation of intra- and extrahepatic tracer accumulations. Apart from the introduction of SPECT/CT, during the study no changes occurred in our angiographic and imaging protocols (including the time from injection of ${ }^{99 \mathrm{~m}} \mathrm{Tc}-\mathrm{MAA}$ ); in the preparation of ${ }^{99 m}$ Tc-MAA; or in the respective quality control measures.

\section{Image Interpretation}

All images were reviewed retrospectively by 2 experienced nuclear medicine physicians. Gastric tracer uptake was interpreted visually as a free ${ }^{99 \mathrm{~m}} \mathrm{Tc}$-pertechnetate concentration or as a ${ }^{99 \mathrm{~m}} \mathrm{Tc}-$ MAA accumulation. Diffuse gastric mucosal uptake, considerably less intense than hepatic tracer uptake and usually accompanied by thyroid uptake, suggested a free ${ }^{99 \mathrm{~m}} \mathrm{Tc}$-pertechnetate accumulation. Focally increased activity in the gastric region was considered a ${ }^{99 m}$ Tc-MAA accumulation, indicating true gastric shunting. Gastric uptake that was initially (in the clinic) viewed as free ${ }^{99 \mathrm{~m}} \mathrm{Tc}-$ pertechnetate was retrospectively classified as equivocal if definitive indicators for free ${ }^{99 \mathrm{~m} T c-p e r t e c h n e t a t e}$ etiology-thyroid uptake and homogeneity of gastric uptake (Fig. 1) —were absent.

\section{Reference Standard and Data Analysis}

Angiographic scans of patients showing extrahepatic accumulation in their ${ }^{99 \mathrm{~m}} \mathrm{Tc}-\mathrm{MAA}$ images were reviewed to find aberrant vessels. Possible underlying arteries were reassessed for coil embolization in a repeated angiography followed by a repeated 99mTc-MAA scan to rule out any remaining extrahepatic shunting. Moreover, a routine angiographic reassessment was performed for all patients just before the start of treatment with ${ }^{90} \mathrm{Y}$ microspheres. For all patients receiving radioembolization, postintervention followup consisting of physical examination and laboratory testing was performed on days $2,14,30,60,90$, and up to $1 \mathrm{y}$ (if the patients were alive). Additionally, esophagogastroduodenoscopy was performed for all patients with gastrointestinal complaints. The results of follow-up and esophagogastroduodenoscopy examinations, along with angiographic findings, served as the reference standard for gastric shunting. To make the results of the 2 subgroups comparable, SPECT/CT findings served as only a part of the reference standard and were not considered for data analysis. For both subgroups, the reference standard was used in calculations of the sensitivity, specificity, positive predictive value, negative predictive value, and accuracy of ${ }^{99 \mathrm{~m}}$ Tc-MAA scanning in the detection of gastric shunting. For statistical analysis, equivocal findings were considered to indicate a gastric concentration of free ${ }^{99 \mathrm{~m}} \mathrm{Tc}$-pertechnetate. Finally, the possible significance of $\mathrm{NaClO}_{4}$ in this regard was investigated applying the Fisher exact test.
A

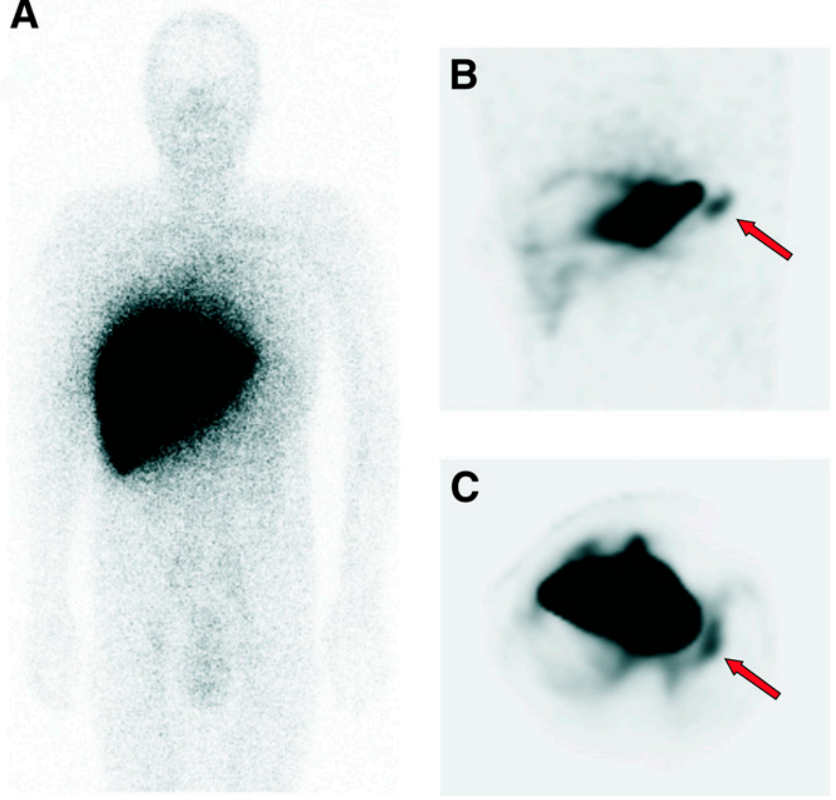

FIGURE 1. Whole-body image (A) and coronal (B) and transaxial (C) SPECT images of subgroup 1 patient with colorectal cancer and hepatic metastases whose gastric uptake was viewed pretherapeutically as free ${ }^{99 \mathrm{~m} T c-p e r t e c h n e t a t e ~(a r r o w s) . ~ F i n d i n g ~ w a s ~ r e t r o-~}$ spectively classified as equivocal because of absence of thyroid uptake. Patient developed posttherapeutic gastrointestinal ulcer.

\section{RESULTS}

\section{First Subgroup}

99mTc-MAA images of the first subgroup demonstrated extrahepatic tracer uptake in the gastric region in 25 studies (29\%). The uptake was interpreted pretherapeutically as a free ${ }^{99 \mathrm{~m}}$ Tc-pertechnetate gastric concentration in 21 studies, 7 of which were rated retrospectively as equivocal and 4 as a ${ }^{99 m}$ Tc-MAA gastric accumulation (Table 1). Thyroid uptake was present in all but 5 studies, 2 of which showed gastric tracer uptake rated as a free ${ }^{99 \mathrm{~m}} \mathrm{Tc}$-pertechnetate gastric concentration.

Review of the angiograms revealed a possible aberrant vessel in 1 of the 4 patients with ${ }^{99 m}$ Tc-MAA deposition in the gastric region. However, because of technical problems, the suspected artery could not be embolized and ${ }^{90} \mathrm{Y}$ microspheres were injected from a more distal catheter position without embolization of the aberrant artery. But the treatment had to be stopped because of reflux of the microspheres, and the patient developed a gastrointestinal ulcer 1 wk later. In another patient with an apparent ${ }^{99 \mathrm{~m}}$ Tc-MAA accumulation in the gastric region, review of the angiographic scans proved him to have an intrahepatic accumulation in only the second segment of his very large liver, not distinguishable from the stomach in 99m Tc-MAA images. The remaining 2 patients with a ${ }^{99 m}$ Tc-MAA gastric accumulation were not treated because no underlying arteries were found on review of the test angiograms or on repeated angiographies.

Of 21 patients with gastric uptake interpreted as a free ${ }^{99 \mathrm{~m}}$ Tc-pertechnetate accumulation, aberrant vessels to the 
TABLE 1

Retrospective Interpretation of Gastric Uptake in 99mTc-MAA Images

\begin{tabular}{|c|c|c|c|c|}
\hline Subgroup & Free ${ }^{99 m}$ Tc-pertechnetate & 99mTc-MAA & Equivocal & No gastric uptake \\
\hline 1 & $14^{*}$ & $4^{\dagger}$ & $7^{\ddagger}$ & $60^{\S}$ \\
\hline 2 & 0 & $2^{\|}$ & 0 & $84^{9}$ \\
\hline \multicolumn{5}{|c|}{$\begin{array}{l}{ }^{*} \text { Aberrant vessels were detected and coiled in } 3 \text { patients, } 2 \text { patients were excluded from treatment because of other contraindications, } \\
\text { and } 1 \text { patient developed gastrointestinal ulcer. Remaining patients }(8 / 14) \text { experienced no relevant side effects after treatment. } \\
{ }^{\dagger} \text { One patient proved to have only intrahepatic accumulation in left lobe of liver, } 1 \text { developed gastrointestinal ulcer, and } 2 \text { were excluded } \\
\text { from treatment. } \\
{ }^{\ddagger} \text { Aberrant vessels were detected and coiled in } 2 \text { patients, } 1 \text { patient was excluded from treatment because of deteriorated liver function, } \\
2 \text { patients developed gastrointestinal ulcer, and } 2 \text { patients experienced no relevant side effects after treatment. } \\
{ }^{\S} \text { Aberrant vessels were detected and coiled in } 11 \text { patients, } 9 \text { patients were excluded from treatment because of other contra- } \\
\text { indications, and } 2 \text { patient developed gastrointestinal ulcer. Remaining } 38 \text { patients experienced no relevant side effects after treatment. } \\
{ }_{\text {A Aberrant vessels were detected and coiled in both patients. }}\end{array}$} \\
\hline
\end{tabular}

gastric region were detected and coiled in the routine angiographic reexamination just before the start of therapy in 5 patients, whereas 3 patients developed a gastrointestinal ulcer during follow-up. ${ }^{99 \mathrm{~m}} \mathrm{Tc}-\mathrm{MAA}$ images were retrospectively classified as equivocal in 4 of these 8 patients, 1 of which was due to the absence of concordant thyroid uptake (Table 1).

Three patients with a free ${ }^{99 \mathrm{~m}} \mathrm{Tc}$-pertechnetate gastric concentration were excluded from radioembolization because of contraindications, and the remaining patients (10/21) underwent treatment without experiencing any relevant side effects (Fig. 2).

In 11 patients, angiographic reexaminations revealed gastric shunting despite an unremarkable ${ }^{99 \mathrm{~m}} \mathrm{Tc}-\mathrm{MAA}$ scan, whereas 2 patients developed gastrointestinal ulcer and 9 patients were excluded from treatment.

Four patients of the first subgroup underwent SPECT/CT in the first week of its use in our institution. All 4 of these patients showed gastric uptake on SPECT/CT images, and the uptake was interpreted at the time as a free ${ }^{99 \mathrm{~m}} \mathrm{Tc}-$ pertechnetate concentration. However, 1 of these patients was among those who developed a posttherapeutic gastrointestinal ulcer, and surgical detection of microspheres in the ulcer strongly disputed the interpretation of the gastric finding as a free ${ }^{99 \mathrm{~m}} \mathrm{Tc}$-pertechnetate concentration.

Altogether, 14 patients of the first subgroup were excluded from treatment with ${ }^{90} \mathrm{Y}$ microspheres because of undetected aberrant arteries despite an extrahepatic ${ }^{99 \mathrm{~m} T c-M A A}$ accumulation in the stomach (2/14) or other parts of the gastrointestinal system (2/14), liver-to-lung shunting higher than $20 \%(5 / 14)$, deteriorated liver function (2/14), or lack of tumoral ${ }^{99 m}$ Tc-MAA accumulation (3/14).

\section{Second Subgroup}

In the second subgroup, an extrahepatic accumulation in the gastric region was observed in only 2 SPECT studies, whereas SPECT/CT images revealed a gastric accumulation in another 5 studies (Fig. 3). The angiographic scans of the second subgroup were reviewed in the same manner as for the first subgroup. Radioembolization was performed on 3 of these 7 patients after an unremarkable ${ }^{99 \mathrm{~m}} \mathrm{Tc}-\mathrm{MAA}$ test after the embolization of possible aberrant vessels, whereas in 2 patients with evident underlying vessels on test angiograms, the vessels were coiled without any further ${ }^{99 m}$ Tc-MAA examination. None of these 5 patients developed gastrointestinal side effects during follow-up. In the other 2 patients with a 99mTc-MAA gastric accumulation, underlying arteries were found neither on review of the test angiograms nor on repeated angiography despite a persistent accumulation seen on SPECT/CT images. These patients were not treated. In the second subgroup, no gastric finding was interpreted as free ${ }^{99 \mathrm{~m}} \mathrm{Tc}$-pertechnetate concentration or as equivocal (8).
A

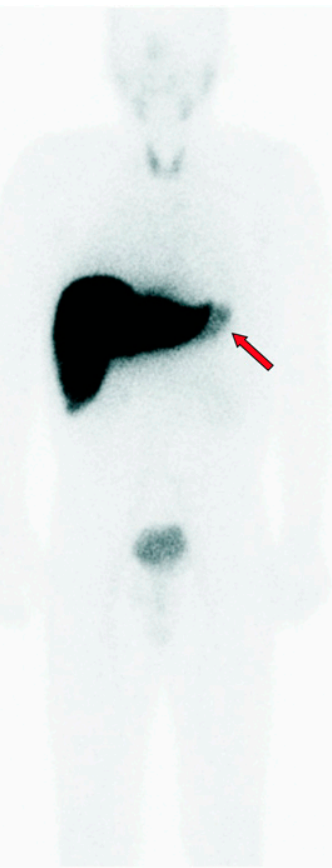

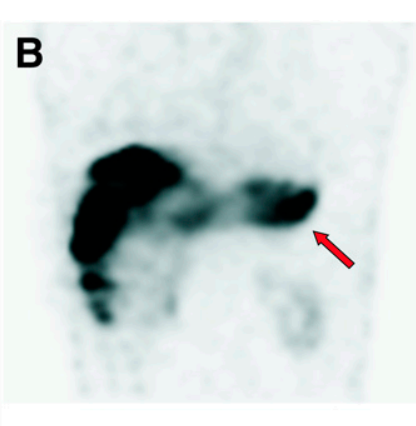

C

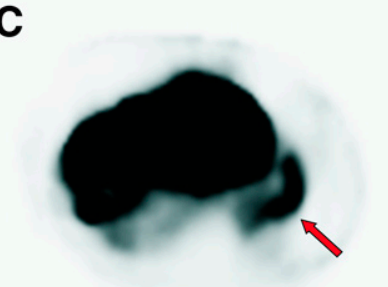

FIGURE 2. Whole-body image (A) and coronal (B) and transaxial (C) SPECT images of subgroup 1 patient with hepatocellular carcinoma who experienced no side effects after treatment. Gastric finding was interpreted as free ${ }^{99 \mathrm{~m} T c-p e r t e c h n e t a t e ~(a r r o w s) . ~}$ 


\section{C

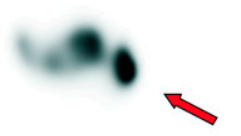

FIGURE 3. Whole-body image (A), coronal (B) and transaxial (C) SPECT images, and SPECT/CT image (D) of subgroup 2 patient with hepatocellular carcinoma who showed gastric accumulation of $99 \mathrm{mTC}-\mathrm{MAA}$. Radioembolization was performed after embolization of aberrant vessels, without any relevant side effects. Extrahepatic uptake (arrows) was optimally localized using SPECT/CT.

\section{Subgroup Comparison}

The sensitivity of ${ }^{99 \mathrm{~m}} \mathrm{Tc}-\mathrm{MAA}$ scanning in detection of gastric shunting was only $12 \%$ in the first subgroup but was raised to $28 \%$ in the second subgroup as a result of complete elimination of any free ${ }^{99 \mathrm{~m}} \mathrm{Tc}$-pertechnetate gastric concentration. Oral administration of $\mathrm{NaClO}_{4}$ before ${ }^{99 m}$ Tc-MAA assessment significantly increased the negative predictive value and accuracy of the test concerning the detection of gastric perfusion from $68 \%$ and $69 \%$, respectively, to $93 \%$ and $94 \%$, respectively $(P<0.001)$. The results of the 2 subgroups are summarized in Table 2 .

\section{DISCUSSION}

Radioembolization of the liver with ${ }^{90}$ Y-microspheres is a novel catheter-based liver-directed modality for treating primary and metastatic liver cancers. An angiographic evaluation combined with ${ }^{99 \mathrm{~m}} \mathrm{Tc}-\mathrm{MAA}$ scanning generally precedes treatment to define the vascular anatomy of the liver, to assess

the vascularity of the hepatic tumors or metastases, and to detect extrahepatic shunting to the lung or gastrointestinal tract (1). Prophylactic embolization of all extrahepatic vessels is also performed to avoid extrahepatic deposition of ${ }^{90} \mathrm{Y}$ microspheres (9). These procedures should be performed as close as possible to the intended time of radioembolization, considering the quick revascularization of these vessels (9). A reassessment arteriogram is also required just before the treatment to ensure that such revascularization has not occurred (6). However, in nearly $4 \%$ of radioembolization cases, microspheres can be transported into the vascular territory of the gastrointestinal organs, resulting in severe damage (10). This occurs when the microspheres are inadvertently injected into small arteries supplying the gut, are misinterpreted as suppliers of the left lobe of the liver, or remain undetected in pretherapeutic tests. Reported complications include gastrointestinal ulceration or bleeding, gastritis or duodenitis, cholecystitis, pancreatitis, and radiation pneumonitis (10-18).

${ }^{99 \mathrm{~m}} \mathrm{Tc}$-pertechnetate concentrates in the brain, thyroid, salivary glands, and gastric mucosa, mediated by plasma membrane glycoprotein sodium-iodine symporter $(19,20)$. To avoid dissociated ${ }^{99 \mathrm{~m} T c-p e r t e c h n e t a t e,}{ }^{99 \mathrm{~m} T c-M A A}$ should be prepared under strict quality control assessments and scintigraphy should be performed within $1 \mathrm{~h}$ of ${ }^{99 \mathrm{~m} T \mathrm{Tc}-\mathrm{MAA}}$ injection. However, ${ }^{99 \mathrm{~m}} \mathrm{Tc}-\mathrm{MAA}$ scans frequently show accumulation of free ${ }^{99 \mathrm{~m}} \mathrm{Tc}$-pertechnetate in radioembolization candidates, hindering accurate evaluation of the gastric region. In such cases, a visual distinction between a free ${ }^{99 m} \mathrm{Tc}-$ pertechnetate concentration and true gastric ${ }^{99 \mathrm{~m}} \mathrm{Tc}-\mathrm{MAA}$ shunting may be difficult, as seen in the 7 of our patients who had to be retrospectively classified as equivocal (Table 1). This limitation considerably reduces diagnostic confidence. Furthermore, gastric accumulation of ${ }^{99 \mathrm{~m} T c}$ MAA can remain unrecognized in the presence of gastric free ${ }^{99 \mathrm{~m}} \mathrm{Tc}$-pertechnetate, as seen in the 4 patients of our cohort with a free ${ }^{99 \mathrm{~m}} \mathrm{Tc}$-pertechnetate concentration, 3 of whom had aberrant vessels found on routine angiographic reexamination whereas 1 developed a posttherapeutic gastrointestinal ulcer.

Perchlorate anion can inhibit sodium-iodine and has been successfully and safely used for prophylaxis of iodineinduced hyperthyroidism before administration of iodinated contrast agents (5-7).

As demonstrated by our second subgroup, without a single equivocal finding, a gastric free ${ }^{99 \mathrm{~m} T c-p e r t e c h n e t a t e}$ concentration can effectively be avoided by oral administration of $\mathrm{NaClO}_{4}$ before the test angiogram. This step considerably facilitates the detection of a gastric accumulation of ${ }^{99 \mathrm{~m} T c-M A A}$ and could significantly increase the negative predictive value and accuracy of the test.

The low overall sensitivity of ${ }^{99 \mathrm{~m} T c-M A A}$ scintigraphy in detecting extrahepatic uptake may be increased to up to $100 \%$ using SPECT/CT methodology $(8,21)$. However, the sensitivity of SPECT/CT is completely dependent on the absence of gastric free ${ }^{99 \mathrm{~m}} \mathrm{Tc}$-pertechnetate. Ruling out ${ }^{99 \mathrm{~m}} \mathrm{Tc}-\mathrm{MAA}$ gastric shunting will be impossible in the presence of a 
TABLE 2

99mTc-MAA in Diagnosis of Gastric Shunting

\begin{tabular}{lccrr}
\hline Subgroup & Sensitivity (\%) & Specificity (\%) & Positive predictive value (\%) & Negative predictive value (\%) \\
\hline 1 & $12(95 \% \mathrm{Cl}, 3-31)$ & $98(95 \% \mathrm{Cl}, 89-99)$ & $67(95 \% \mathrm{Cl}, 30-95)$ & $68(95 \% \mathrm{Cl}, 58-79)$ \\
2 & $28(95 \% \mathrm{Cl}, 8-64)$ & $100(95 \% \mathrm{Cl}, 87-100)$ & $100(95 \% \mathrm{Cl}, 34-100)$ & $93(95 \% \mathrm{Cl}, 85-97)$ \\
& & & & \\
\multicolumn{2}{l}{$\mathrm{Cl}=$ confidence interval. }
\end{tabular}

free ${ }^{99 m}$ Tc-pertechnetate accumulation even when SPECT/ CT is applied, as observed in 1 of our 4 patients in the first subgroup who developed posttherapeutic gastrointestinal ulcer.

This study had some limitations. Because a SPECT/CT system was not available at the time of the $99 \mathrm{~m}$ Tc-MAA assessments of nearly half our patients, and in order to make the results of the 2 subgroups comparable, we did not consider the SPECT/CT findings in the data analysis. These data could have dramatically enhanced the ${ }^{99 m}$ Tc-MAA test sensitivity, as has already been shown by other studies $(8,21)$. However, the use of SPECT/CT is not expected to replace the need for $\mathrm{NaClO}_{4}$ administration to achieve a confident evaluation of the gastric region. In addition, the chronologic division of our 2 subgroups may also be statistically influential because of the improvement in angiographic techniques over time. The other principal limitation of this study was its retrospective nature and the absence of paired comparisons, which will inevitably affect the strength of conclusions.

\section{CONCLUSION}

The administration of oral sodium perchlorate before ${ }^{99 m}$ Tc-MAA assessment results in effective avoidance of a gastric concentration of free ${ }^{99 \mathrm{~m}} \mathrm{Tc}$-pertechnetate and, consequently, of equivocal extrahepatic findings in the gastric region. These benefits increase test sensitivity and accuracy and save time in reviewing the angiograms. Hence, the oral administration of $\mathrm{NaClO}_{4}$ should be an integral part of patient preparation directly before angiography in order to improve treatment planning and reduce therapeutic side effects.

\section{DISCLOSURE STATEMENT}

The costs of publication of this article were defrayed in part by the payment of page charges. Therefore, and solely to indicate this fact, this article is hereby marked "advertisement" in accordance with 18 USC section 1734.

\section{ACKNOWLEDGMENT}

No potential conflict of interest relevant to this article was reported.

\section{REFERENCES}

1. Denecke T, Ruhl R, Hildebrandt B, et al. Planning transarterial radioembolization of colorectal liver metastases with yttrium 90 microspheres: evaluation of a sequential diagnostic approach using radiologic and nuclear medicine imaging techniques. Eur Radiol. 2008;18:892-902.

2. McLean JR, Welsh WJ. Radiochemical impurities in ${ }^{99 m}$ Tc-MAA preparations. Nuklearmedizin. 1977;16:143-144.

3. McLean JR. Rapid assay for total unbound Tc-99m in preparations of Tc-99m in macroaggregated albumin: concise communication. J Nucl Med. 1978;19: 1045-1048.

4. McLean JR, Welsh WJ, Rockwell LJ. Quality control procedures for ${ }^{99 \mathrm{~m} T c-}$ MAA. Int J Nucl Med Biol. 1979;6:142-143.

5. Nolte W, Müller R, Siggelkow H, Emrich D, Hufner M. Prophylactic application of thyrostatic drugs during excessive iodine exposure in euthyroid patients with thyroid autonomy: a randomized study. Eur J Endocrinol. 1996;134:337-341.

6. Wolff J. Transport of iodide and other anions in the thyroid gland. Physiol Rev. 1964;44:45-90.

7. Lawrence JE, Lamm SH, Braverman LE. The use of perchlorate for the prevention of thyrotoxicosis in patients given iodine rich contrast agents. J Endocrinol Invest. 1999;22:405-407.

8. Ahmadzadehfar H, Sabet A, Biermann K, et al. The significance of ${ }^{99 m}$ Tc-MAA SPECT/CT liver perfusion imaging in treatment planning for ${ }^{90} \mathrm{Y}$-microsphere selective internal radiation treatment. J Nucl Med. 2010;51:1206-1212.

9. Kennedy A, Nag S, Salem R, et al. Recommendations for radioembolization of hepatic malignancies using yttrium-90 microsphere brachytherapy: a consensus panel report from the radioembolization brachytherapy oncology consortium. Int J Radiat Oncol Biol Phys. 2007;68:13-23.

10. Carretero C, Munoz-Navas M, Betes M, et al. Gastroduodenal injury after radioembolization of hepatic tumors. Am J Gastroenterol. 2007;102:1216-1220.

11. Murthy R, Nunez R, Szklaruk J, et al. Yttrium-90 microsphere therapy for hepatic malignancy: devices, indications, technical considerations, and potential complications. Radiographics. 2005;25(suppl 1):S41-S55.

12. Ahmadzadehfar H, Biersack HJ, Ezziddin S. Radioembolization of liver tumors with yttrium-90 microspheres. Semin Nucl Med. 2010;40:105-121.

13. Salem R, Thurston KG. Radioembolization with ${ }^{90}$ yttrium microspheres: a stateof-the-art brachytherapy treatment for primary and secondary liver malignancies. Part 1: Technical and methodologic considerations. J Vasc Interv Radiol. 2006; 17:1251-1278.

14. Leung TW, Lau WY, Ho SK, et al. Radiation pneumonitis after selective internal radiation treatment with intraarterial ${ }^{90}$ yttrium-microspheres for inoperable hepatic tumors. Int J Radiat Oncol Biol Phys. 1995;33:919-924.

15. Murthy R, Brown DB, Salem R, et al. Gastrointestinal complications associated with hepatic arterial yttrium-90 microsphere therapy. J Vasc Interv Radiol. 2007; 18:553-561.

16. Salem R, Parikh P, Atassi B, et al. Incidence of radiation pneumonitis after hepatic intra-arterial radiotherapy with yttrium-90 microspheres assuming uniform lung distribution. Am J Clin Oncol. 2008;31:431-438.

17. Yip D, Allen R, Ashton C, Jain S. Radiation-induced ulceration of the stomach secondary to hepatic embolization with radioactive yttrium microspheres in the treatment of metastatic colon cancer. J Gastroenterol Hepatol. 2004;19: 347-349.

18. Atassi B, Bangash AK, Lewandowski RJ, et al. Biliary sequelae following radioembolization with yttrium-90 microspheres. J Vasc Interv Radiol. 2008; 19:691-697.

19. Andros G, Harper PV, Lathrop KA. Pertechnetate- 99 m localization in man with applications to thyroid scanning and the study of thyroid physiology. J Clin Endocrinol Metab. 1965;25:1067-1076.

20. De La Vieja A, Dohan O, Levy O, Carrasco N. Molecular analysis of the sodium/ iodide symporter: impact on thyroid and extrathyroid pathophysiology. Physiol Rev. 2000;80:1083-1105.

21. Hamami ME, Poeppel TD, Muller S, et al. SPECT/CT with ${ }^{99 m}$ Tc-MAA in radioembolization with ${ }^{90} \mathrm{Y}$ microspheres in patients with hepatocellular cancer. J Nucl Med. 2009;50:688-692. 